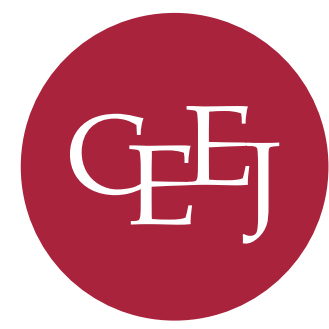

Central European

Economic Journal

ISSN: 2543-6821 (online). Journal homepage: http://ceej.wne.uw.edu.pl

\title{
Comparison of Block Maxima and Peaks Over Threshold Value-at-Risk models for market risk in various economic conditions
}

Filip Szubzda, Marcin Chlebus

To cite this article: Szubzda, F., Chlebus, M. (2019). Comparison of Block Maxima and Peaks Over Threshold Value-at-Risk models for market risk in various economic conditions. Central European Economic Journal, 6(53), 70-85.

DOI: 10.2478/ceej-2019-0005.

To link to this article: https://doi.org/10.2478/ceej-2019-0005 


\title{
Central European Economic Journal
}

\author{
Filip Szubzda ${ }^{(\mathbb{D})}$ Marcin Chlebus ${ }^{1}(\mathbb{D})$
}

1 Faculty of Economic Sciences, University of Warsaw, corresponding author: mchlebus@wne.uw.edu.pl

\section{Comparison of Block Maxima and Peaks Over Threshold Value-at-Risk models for market risk in various economic conditions}

\begin{abstract}
The aim of the presented study was to assess the quality of VaR forecasts in various states of the economic situation. Two approaches based on the extreme value theory were compared: Block Maxima and the Peaks Over Threshold. Forecasts were made on the daily closing prices of 10 major indices in European countries, divided into two groups: emerging countries (Bulgaria, Czech Republic, Lithuania, Latvia, Poland, Slovakia and Hungary) and developed countries (England, France and Germany). Three states of economic situation were analysed: the pre-crisis (2007), the crisis (2008) and the post-crisis (2009) period as out-of-sample. The main conclusion obtained is the too slow process of adapting static EVT-based forecasts to market movements. While in the pre-crisis period the results were satisfactory, in the period of crisis VaR forecasts were too often exceeded.
\end{abstract}

Keywords: Value-at-Risk, extreme value theory, forecasting, market risk

JEL Codes: C53, C58, G17

\section{Introduction and literature review}

Market risk is understood as the risk of loss of value maintained by the financial intuition of the portfolio. It may result from changes in the prices of shares held, the level of credit spreads, changes in the exchange rate, changes in commodity prices and other indicators in which value is dependent and determined on the financial market. The main method of measuring such a risk is the Value at Risk. This term is understood as the maximum loss observable on the market at the given confidence level under normal market conditions (Abad, Benito, \& Lopez, 2013).

The main advantage of VaR method is the ease of interpretation. $\mathrm{VaR}$ enables direct comparison of the risk of several financial instruments. However, it has also its limitations. First, the calculated VaR does not say how big a potential loss would be if the loss would exceed the calculated VaR. The exceedance may be minimal according to forecast level or it may be exposing the institution to significant losses. Secondly, $\mathrm{VaR}$ is not a coherent measure, not fulfilling the subaddition assumption (Artzner, Eber, \& Heath, 1999). Both problems are solved by the Expected Shortfall (ES) measure, which is to replace VaR in estimating market risk (due to announcements of the Basel Committee of Banking Supervision). The ES is defined as an expected value of losses above the VaR. This makes the usefulness of VaR estimation methods unchanged.

The VaR forecasting methods can be divided into parametric, non-parametric and semi-parametric groups (Abad et al., 2013). In non-parametric methods, the VaR measure is calculated directly on the basis of empirical data. The historical simulation is the most popular of this group of methods, based on quantiles of empirical data distribution. Predictions based on parametric methods measure the risk by fitting empirical data to theoretical probability distributions, by estimating the parameters of the assumed distributions. This group includes primarily the models of the Generalized Autoregressive 
ConditionalHeteroskedasticity (GARCH), Exponentially Weighted Moving Average (EWMA) and Stochastic Volatility (SV). Semi-parametric methods combine both above-mentioned groups. The most important methods from this collection are volatility-weighted historical simulation, filtered historical simulation, Monte Carlo simulation, CaViaR model and methods based on the extreme value theory (EVT).

Many studies indicate that distributions of financial data do not belong to the normal distribution (Bollerslev, Todorov, \& Li, 2013; Engle \& Patton, 2001; Pagan, 1996). They are better described by stylised facts that they are characterised by, among others, volatility clustering and heavy tails. In this situation, classic estimation methods, based on the Gaussian probability distribution, may underestimate market risk, exposing financial institutions to significant losses. The problem of heteroscedasticity of financial data is solved by ARCH class models (Engle, 1982), and the generalised ARCH models - GARCH class models (Bollerslev, 1986). In $\mathrm{VaR}$ forecasts based on these models, the quantiles of normal distribution or Student- $t$ distribution are mainly used. However, various techniques are being developed to take into account other distributions, for example, the distributions of the EVT. The latest literature shows higher efficiency of $\mathrm{VaR}$ forecasts using models that use the EVT rather than the classic GARCH models (Allen, Singh, \& Powell, 2011; Bee \& Miorelli, 2010; Bhattacharyya \& Ritolia, 2008; Bystrom, 2001; Darbha, 2001; Ergun \& Jun, 2010; Manganelli \& Engle, 2001; Marimoutou, Raggad, \& Trabelsi, 2009). Similar results are also obtained by the GARCH model using the Student- $t$ distribution compared with the basic GARCH model (Gencay, Selcuk, \& Ulugulyagci, 2003; Marimoutou et al., 2009).

Non-parametric methods are equally popular methods of VaR forecasts - historical simulation and variance-covariance method. These methods, however, are usually out-classified by elaborate parametric or semiparametric models. Angelidis, Benos, and Degiannakis (2007) checked the effectiveness of historical simulation, the variance-covariance method and 16 methods from the GARCH and EVT family. The main conclusion of their work is the better behaviour of predictions based on EVT for higher confidence levels. Similar conclusions were reached by Flugentiusson (2012), Nozari, Raei,
Jahanguin, and Bahramgiri (2010), Gencay and Selcuk (2004) and Alves and Santos (2013).

The EVT models can be divided into unconditional and conditional (using the GARCH process for modelling the conditional heteroscedasticity) (Abad et al., 2013). The present study compared the unconditional (static) models. Static methods based on the EVT are divided into two approaches: the Block Maxima (BM) and the Peaks Over Threshold (POT). There is no unambiguous answer which one is more effective. On financial data, Flugentiusson (2012) indicates the BM method as inferior to the POT method, and similar results are presented by Marinelli et al. (2007) and Caires (2009). BM is more often and more effectively used in hydrology (Abad et al., 2013; Bommier, 2014). Da Silva and de Melo Mendes (2003), however, receive satisfactory results for Asian financial markets using the BM method. The advantage of one of these methods is therefore not deterministic and depends on the available data.

The works comparing the efficiency of individual methods in different states of the economic situation are important from the point of view of limiting market risk. Bao, Lee, and Saltoglu (2006) used data from the Asian financial markets in periods before, during and after the crisis. The pre- and post-crisis results indicated the superiority of RiskMetrics ${ }^{\circledR}$ methods, while the most effective methods during the crisis were based on the EVT. In the Bystrom study (2001), the GARCH methods based on the EVT turn out to be the best both in the period of calm (before or after the crisis) and in increased volatility (crisis). Kourouma, Dupre, Sanfilippo, and Taramasco (2010) compare VaR based on historical simulation method based on EVT for main indices of American and French market during 2008 crisis. Their results indicate that the EVT method performs better during periods of higher volatility. Mutu, Balogh, and Moldovan (2011) compared the performance of VaR models (HS, EWMA, GARCH, EVT) for Eastern and Central European countries main indices. Authors analysed period from 2004 to 2009 and indicated that EVT and GARCH can effectively measure the risk of capital market and satisfy the requirements of the investors in periods characterised by extreme events.

Based on the discussed literature, it is justified to compare the quality of $\mathrm{VaR}$ forecasts obtained on the 
basis of various models based on the EVT. The latest literature indicates this group of models as potentially the best one in VaR forecasting for market risk. However, researchers analysing their quality in various states of the economy indicate that in some periods these models are worse than more classic models. In addition, these models are quite conservative in $\mathrm{VaR}$ forecasting (low $\mathrm{VaR}$ forecasts levels are expected), therefore relatively high costs of their application in practice are expected. In the present study, the effectiveness (quality and costs of use) in the VaR forecasting of static methods based on the EVT in various states of the economic situation was analysed. Before the results of the study are presented, the next section will illustrate its methodology.

\section{Methods}

\subsection{Value at Risk}

Value at Risk is, in the normal market situation, the maximum loss observable at the given confidence level $1-\alpha \cdot \mathrm{VaR}$ is a quantile of the selected order $\alpha$ of a given distribution. It is expressed by the formula:

$$
P\left(r_{t}\left\langle\operatorname{VaR}_{\alpha}(t)\right| \Omega_{t-1}\right)=\alpha
$$

where $r_{t}$ is a return on assets in the period $t, \operatorname{VaR}_{\alpha}(t)$ is the Value-at-Risk forecast in the $t$ period and $\mathbf{U}_{t-1}$ is a set of information available in the $t-1$ period.

According to the Basel recommendations (BCBS, 1996), the basic method of assessing the quality of VaR forecasts is the traffic light backtest method. In the test, three backtesting zones are distinguished: green, when the number of exceedances is set between 0 and 4 - the model is precise; yellow, when the number of exceedances is in the range from 5 to 9 - the semi-precise model; red - when there is more than 10 exceedances the imprecise model. These numbers refer to a period of 250 observations and are based on a right-side binominal test with an assumed 1\% exceedance probability.

\subsection{Extreme value theory}

The EVT models focus on the tail of the data distribution. The main objective of EVT is to make assumptions about distribution of sample built on extrema (maxima or minima) possessed from analysed data set.

There are two main approaches: BM and POT (Abad et al., 2013). The main difference between the methods is the way of obtaining extreme observations from data. In BM method, a sample is divided into subsamples (i.e. equal time intervals - weeks, months, quarters) and set of maximum/minimum observations from each subsample constitutes a sample of extremes. While in the POT method, a given cut-off threshold $u$ is set. All observations below the $u$ threshold form a set of observations used to estimate the tail of a distribution.

\subsubsection{Block Maxima}

The BM consists in dividing the set of data into $M(m=1$, $2, \ldots, M)$ time intervals of length $n$ each. Values used for estimation are the minimums or maximums observed in subsequent $M$ time intervals. In other words, if $X_{1} m, X_{2} m, \ldots, X_{n} m$ is a sequence of independent and identically distributed random variables from a time interval $m$, the maximum values can be defined as $M_{m}=\max \left(X_{1} m, \ldots, X_{n}, m\right)$. The minimum values can be defined analogously by reversing their sign. To find a non-degenerated cumulative distribution function (cdf), the maximum values $M_{m}$ are standardised by the scale parameter (variance) $\sigma_{m}$ and the expected value $\mu_{m}$ $\left(S_{m}=\left(M_{m}-\mu_{m}\right) / s_{m}\right)$.

According to the Fisher and Tippett (1928), if such a non-degenerate cdf exists (FM), it must belong to one of the Gumbel, the Frechet or the Weibull distributions. Those distributions can be interpreted as special cases of generalised extreme value (GEV) distribution. The cdf of this distribution is defined as follows (with a shape parameter $x$ ):

$\operatorname{GEV}(x ; \xi, \mu, \sigma)=\left\{\begin{array}{l}\exp \left[-\left(1+\xi\left(\frac{x-\mu}{\sigma}\right)\right)^{-\frac{1}{\xi}}\right] \text { if } \xi \neq 0 \text { and }\left(1+\frac{\xi(x-\mu)}{\sigma}\right)>0 \\ \exp \left[-\exp \left(-\left(\frac{x-\mu}{\sigma}\right)\right)\right] \quad \text { if } \xi=0\end{array}\right.$

The $x$ sign determines which of the distributions has been selected. The Gumbel, Frechet or Weibull distribution is assumed for $x=0, x>0$ and $x<0$, respectively (Da Silva \& de Melo Mendes, 2003). In the research, a method 
of the maximum likelihood was used to estimate the distribution parameters.

From the GEV distribution, a VaR can be estimated as follows:

$$
= \begin{cases}\hat{\mu}_{n}-\frac{\hat{\sigma}_{n}}{\hat{\xi}_{n}}\left(1-(-n \ln (\alpha))^{-\hat{\xi} n}\right) & \operatorname{VaR}(\alpha) \\ \hat{\mu}_{n}-\hat{\sigma}_{n} \ln (-n \ln (\alpha)) & \text { to } \xi>0 \text { (Fréchet) }\end{cases}
$$

where $\operatorname{VaR}(\alpha)$ is the measure of the Value at Risk at the significance level $\alpha, \hat{\mu}$ is the estimated location parameter, $\hat{\sigma}$ is the estimated scale parameter and $\hat{\xi}$ is the estimated shape parameter.

\subsubsection{Peaks Over Threshold}

The POT method distinguishes two approaches: the approach based on the Hill estimator and the approach based on the assumption that the tail of the return rate distribution is derived from the generalised Pareto distribution (GPD). In the following research, the method based on the GPD (Balkema \& de Haan, 1974; Pickands, 1975) will be used and described. The GPD cumulative distribution function is as follows:

$$
\operatorname{GPD}(x ; \xi, \mu, \sigma)= \begin{cases}1-\left(1+\xi \frac{x-\mu}{\sigma}\right)^{-\frac{1}{\xi}} & \xi \neq 0 \\ 1-\exp \left(-\frac{x-\mu}{\sigma}\right) & \xi=0\end{cases}
$$

where $m$ is the location parameter, $s$ is the scale parameter and $x$ is the shape parameter.

In this case, a series of random variables $X_{1}, X_{2}, \ldots$, $X_{c}$ (i.i.d.) and certain threshold level $u$ are considered. Assuming that right tail of a distribution is of interest, for all realisations $x i$ above the threshold $u$ the values of exceedances $y_{1}, y_{2}, 1 / 4, y n$ are calculated $\left(y_{i}=x_{i}-u\right.$ ). The distribution of exceedances above the $u$ threshold is defined as:

$$
F_{u}(x ; u)=P(X=u+y \mid X>u)=\frac{F(y+u)-F(u)}{1-F(u)}
$$

Assuming that for a certain threshold $u$ the distribution of observations being above the threshold is the $\operatorname{GPD}(y ; \sigma, \mu, \xi)$, the tail of the distribution of the return rates above the assumed cut-off point can be written as follows:

$F(x)=F(y+u)=[1-F(u)] \operatorname{GPD}(y ; \sigma, \mu, \xi)+F(u)$

where $F($.$) is a cumulative distribution function, u$ is the cut-off threshold, $y$ is a loss level above the cut-off threshold $u$ and $G_{\xi, \sigma}(y)$ is the cumulative distribution function value of the GPD.

Value at Risk at the a level is calculated from the following formula:

$\operatorname{VaR}(\alpha)=u+\frac{\hat{\sigma}}{\hat{\xi}}\left[\left[\frac{n}{N_{u}}(1-\alpha)\right]^{-\hat{\xi}}-1\right]$

where $\operatorname{VaR}(\alpha)$ is Value at Risk at the significance level $a, u$ is the cut-off threshold, $\hat{\xi}, \hat{\sigma}$ are GPD parameters, $n$ is the total number of the analysed return rates, $N_{u}$ is the number of return rates below the cut-off point $u$.

Also, in this case, the maximum likelihood method was used to estimate the parameters. A mean excess plot was used for determining the cut-off threshold $u$ (Embrechts, Kluppelberg, \& Mikosch, 1997).

\subsubsection{Evaluating the quality of forecasts}

In the study, the Value at Risk forecasts were compared on the basis of the number of losses exceeding the estimated VaR, traffic light backtest, Kupiec test (1995), backtesting criterion statistics (Abad et al., 2013), Christoffersen test (1998) and the cost functions: the absolute cost function of Abad and Benito (Abad et al., 2013), the Caporin function (2008) measuring the absolute cost of the forecast and the function of the excessive cost (see Chlebus, 2014).

The Kupiec test compares the expected and observed share of exceeded $\mathrm{VaR}$ forecasts, and the zero hypothesis is the equality between the expected and observed share of exceedances. This test, however, is not able to determine the direction of error (overestimation or underestimation). Backtesting criterion statistics allows 
verification of the error direction. Strongly negative values suggest an overestimation of VaR forecasts, while positive ones indicate an underestimation of forecasts. Christoffersen test extends the Kupiec test with the test of the independence of exceedances - when the intervals between exceedances are too small, it means that the model incorrectly estimates the risk during volatility clustering periods.

The applied cost functions do not have the character of a formal test. Lopez (1999) described square cost function which increases the weight of severe exceedances, but hinders the interpretation of the results. The cost function of Abad and Benito is more straightforward in interpretation as it takes into account the absolute value of the difference between forecasts and real observed values when exceedance occurred. The sum of these differences divided by the number of periods at the observed $\mathrm{VaR}$ exceedance is the average severity of the exceedance per VaR forecast. In this method, the average is taken into account, and not the sum of the severity of the exceedances, so that this measure does not take into account the number of exceedances. The Caporin function takes into account both the exceedances and the underestimation of the forecast. The result of this function is the mean absolute error of the VaR forecast. In the work a function similar to the Caporin function is also used, but distinguishing the measurement of effectiveness in three variants: in the case of exceeding the $\mathrm{VaR}$ forecast by the observed return rate, in the case when the VaR forecast is smaller than the observed return rate and at the same time the observed return rate is higher than zero and in the case when the VaR forecast is lower than the observed return rate but the observed return rate is smaller than zero. The average value of the excessive cost function is used to compare the models. The higher the result of the mean value of the excessive cost function, the more conservative the model, that is, $\mathrm{VaR}$ forecasts are too high in relation to the needs related to the coverage of possible losses.

Summing up, the Kupiec test, backtesting criterion and Christoffersen test are used to examine whether the forecasts perform correspondingly to Basel postulates. The loss functions, such as the absolute cost function of Abad and Benito, the Caporin function and the function of the excessive cost, check if the costs of using such techniques are economically reasoned for financial institution.

\section{Empirical study}

\subsection{Data collection}

The study was conducted on data concerning the daily closing prices of individual stock exchange indices expressed as a logarithmic rate of return. Ten European markets were analysed - seven emerging and three developed. The following Central-Eastern European countries were included in the emerging countries group: Bulgaria (SOFIX), Czech Republic (PX), Lithuania (OMXV), Latvia (OMXR), Poland (WIG20), Slovakia (SAX) and Hungary (BUX). The group of developed countries include England (UKX), France (CAC) and Germany (DAX). The study distinguishes three periods: period I: pre-crisis, in which the in-sample period is between 01 January 2000 and 31 December 2006, and out-of-sample between 01 January 2007 and 31 December 2007. Period II: crisis, in which the in-sample period is between 01 January 2000 and 31 December 2007, and out-of-sample between 01 January 2008 and 31 December 2008. Period III: post-crisis, in which the in-sample period is between 01 January 2000 and 31 December 2008, and out-of-sample between 01 January 2009 and 31 December 2009. The adopted thresholds for the periods analysed were arbitrarily set, recognising that 2008 was the axis of the financial crisis in all analysed countries. The main reason for choosing 7-year in-sample period is that EVT techniques are built on extreme returns observed in the past. Therefore, the data collection needs longer periods to be large enough to be representative. The period between 2000 and 2007 contains periods of calm and also periods of increased volatility (i.e. the beginning of the decade). Table 1 presents basic descriptive statistics for the return rates for individual indices in 2000-2009. The return rates in all cases come from a different distribution than the normal one (JarqueBera test; $p$ value $<0.0001$ ). In most cases, the skewness coefficient is relatively close to 0 . The exceptions are Bulgaria, Czech Republic and Latvia. Analysing the quantiles of distributions, it can be noticed that the left skewness tendency results mainly from the left long tail in its final parts (the distribution body is relatively symmetrical). The coefficient of excessive kurtosis in each case indicates the leptokurtosis of distributions. 
Tab. 1: Descriptive statistics of time series of return rates from stock exchange indices from 2000 to 2009

\begin{tabular}{lccccccccccccc}
\hline Country & Avg & Min & SD & 1P & Q1 & Med & Q3 & 99P & Max & Sk & Kurt & JB & Cap \\
\hline Emerging countries & & & & & & & & & & & \\
\hline Bulgaria & 0.08 & -11.36 & 1.59 & -5.03 & -0.52 & 0.08 & 0.69 & 4.99 & 8.39 & -0.50 & 6.78 & 0.00 & 7 \\
\hline Czech R & 0.03 & -16.18 & 1.59 & -4.21 & -0.73 & 0.07 & 0.84 & 3.70 & 12.36 & -0.49 & 12.07 & 0.00 & 37 \\
\hline Lithuania & 0.03 & -10.22 & 1.07 & -3.33 & -0.32 & 0.00 & 0.42 & 2.87 & 11.00 & -0.18 & 18.93 & 0.00 & 4 \\
\hline Latvia & 0.04 & -14.70 & 1.62 & -4.82 & -0.51 & 0.02 & 0.61 & 4.75 & 10.18 & -0.73 & 14.83 & 0.00 & 1 \\
\hline Poland & 0.01 & -8.44 & 1.73 & -4.47 & -0.96 & 0.00 & 0.94 & 4.56 & 8.15 & -0.09 & 1.81 & 0.00 & 178 \\
\hline Slovakia & 0.05 & -9.58 & 1.23 & -3.69 & -0.34 & 0.00 & 0.46 & 3.85 & 11.88 & -0.16 & 10.73 & 0.00 & 5 \\
\hline Hungary & 0.04 & -12.65 & 1.68 & -4.17 & -0.88 & 0.05 & 0.94 & 4.42 & 13.18 & -0.13 & 5.82 & 0.00 & 21 \\
\hline Developed countries & & & & & & & & & & & \\
\hline England & -0.01 & -9.27 & 1.34 & -4.02 & -0.64 & 0.03 & 0.66 & 3.50 & 9.38 & -0.12 & 6.11 & 0.00 & 3019 \\
\hline France & -0.02 & -9.47 & 1.58 & -4.43 & -0.77 & 0.02 & 0.78 & 4.07 & 10.60 & 0.03 & 4.95 & 0.00 & 1823 \\
\hline Germany & 0.00 & -8.88 & 1.68 & -5.04 & -0.84 & 0.07 & 0.85 & 4.68 & 10.80 & 0.04 & 4.21 & 0.00 & 1486 \\
\hline
\end{tabular}

Source: https:// data.worldbank.org/indicator/CM.MKT.LCAP.CD.

The specificity of the analysed time series justifies the appropriateness of the EVT models, the thick left-sided tail of the distribution.

Ave, average; Min, minimum value; SD, standard deviation; $1 \mathrm{P}$ - first percentile, $1 \mathrm{Q}$ - first quartile, $3 \mathrm{Q}$ - third quartile, 99P - 99 percentile, Max, maximum value; Sk, skewness coefficient; Kurt, excessive Kurtosis coefficient; $\mathrm{JB}, p$ value of Jarque-Bera test; Cap, capitalisation in 2006 in billions of USD.

\subsection{VaR forecast}

In the study, the Value-at-Risk forecasts were compared for three EVT models: POT and BM with a monthly and bimonthly time interval.

One-day-head VaR forecasts were estimated using the rolling time window method. First out-of-sample forecast was received by estimating VaR with the use of entire in-sample data. Forecast for the second trading day was estimated with the use of in-sample data excluding the first observation but with the use of first realised out-of-sample observation instead. This procedure is repeated until the out-of-sample period ends (approximately 250 times), meaning that in-sample observation window is moved by one period (one day) each time.
For each time window, the extreme observations are obtained as described in Methods section. Due to the use of working days only, 21 observations were adopted in the BM method for 1 month block, and 42 observations in 2 months block method.

Tables 2-4 present the results of the previously discussed measures of VaR forecasts effectiveness: LP - number of exceedances, Kupiec - test statistics and $p$ value of the Kupiec test, Christoff - test statistics and the $p$ value of Christoffersen test, $T_{\mathrm{BP}}$ - test statistics and the $p$ value of the Backtesting criterion statistics, $\mathrm{A} \& \mathrm{~B}-$ value of the Abad and Benito function, Caporin - value of the Caporin function, CAE - value of the cost function distinguishing three cases. In addition, Tables 2-4 also estimated the maximum expected loss value on the first day of the out-of-sample period at a confidence level of $99 \%$. This value will allow to compare the level of risk at the beginning of three analysed periods.

\subsubsection{Period I: pre-crisis}

The first discussed out-of-sample period is the pre-crisis period that is between 01 January 2007 and 31 December 2007. The results are presented in Table 2. Forecasts for all indices, with the exception of the Lithuanian one, can 
be considered as precise based on the results of the Basel traffic light test. Only the OMXV index has semi-precise forecasts for the POT method. Similar conclusions can be drawn from the analysis of unconditional coverage tests (Kupiec and Backtesting criterion statistics) and conditional coverage test (Christoffersen). Based on the results obtained from them, it can be noticed that for all three tests the null hypothesis is simultaneously rejected only for the Lithuanian index in the POT method - when the number of exceedances is relatively large. The Kupiec test indicates that the total absence of exceedances should also be considered as a statistical discrepancy between the expected and observed share of exceedances in most of the cases - null hypothesis should not be rejected in 5 of 30 discussed time series.

The results of the Abad and Benito functions indicate that even though the exceedances occur, their magnitude is rather not severe. The Caporin and CAE functions describe the average absolute error in relation to the observed return rate. The results in each country are similar and it is noticeable that both $\mathrm{BM}_{21}$ and $\mathrm{BM}_{42}$ methods are more conservative than POT method and therefore they can be considered to be more expensive for financial institutions to implement.

The obtained results indicate that the unconditional EVT models for the pre-crisis period allow to obtain satisfying VaR forecasts in terms of their quality but it may involve higher costs of applying the selected models. No quintessential differences were observed between individual countries within emerging and developing groups. The distinction between both groups is also rather imperceptible based on the results shown in Table 2.

\subsubsection{Period II: crisis}

In the second period, one can observe a clear deterioration of results. The models are not able to quickly adjust data to the observed drops in the market. Satisfactory results are obtained only by the Slovak market for each method and by all indices using the BM methods, excluding Czech and Hungarian markets. The rest of the results, according to the Basel recommendations, can be classified into semi-precise or imprecise. The Kupiec test indicates that the hypotheses about the correctness of the forecast should be rejected in the Slovakian and German markets for the BM method with both 1- and 2-month blocks and also for all POT cases. The test statistics of the Backtesting criterion statistics is definitely positive in most of the POT cases, which confirms the underestimation of the forecasts.

The cost function of Abad and Benito indicates differences between the return rates and the VaR forecasts at the point of exceedance especially for POT method. The Caporin and CAE functions are similar to the results obtained from Table 2. They suggest an overestimation of the forecast in moments of calm, and underestimation of forecasts in moments of intensified market movements. The Caporin function most often indicates the smallest mean absolute error of the VaR forecast for POT methods.

During the crisis period, the unconditional EVT models fail. On the one hand, both BM methods are able to limit number of exceedances, but on the other it is highly uneconomic from bank's perspective. POT method leads to significant underestimation of VaR due to the slow adaptation to new market conditions.

In this case, differences between countries are noticeable. The Czech Republic, Slovakia and Hungary are characterised with similar VaR levels, that is, around $7 \%-8 \%$ for BM methods and around 3.5\% for POT method. The similarity between these indices can be explained with the fact that these three countries are neighbours and their trading connections are strongly related. This observation could lead to expansion of the research on VaR forecasts, using additional information of connections and correlations between two or more examined parties.

Another observed remark is connected with Table 1. Even though the capitalisation between emerging and developed countries is clearly different, Polish market distinguishes in its group and in terms of capitalisation it is the closest to developed countries group. According to the results from Table 3, the similarities are also noticeable. Number of exceedances is especially similar to English and French market. Simple mean average for CAE function in developed countries is 0.036 for $\mathrm{BM}_{21}$, 0.042 for $\mathrm{BM}_{42}$ and 0.021 for POT methods. These scores are prominently close to the scores obtained by the Polish market. 
Tab. 2: VaR forecasts for individual countries in period I

\begin{tabular}{|c|c|c|c|c|c|c|c|c|}
\hline & VaR 99\% & EX & Kupiec & Christoff & $T_{\mathrm{BP}}$ & A\&B & Caporin & CAE \\
\hline \multicolumn{9}{|c|}{ Emerging countries } \\
\hline \multicolumn{9}{|c|}{ Bulgaria (SOFIX) } \\
\hline $\mathrm{BM}_{21,1}$ & 12.91 & 0 & $4.99(0.03)$ & $4.99(0.08)$ & $-1.58(0.11)$ & $<0.001$ & 0.182 & 0.074 \\
\hline $\mathrm{BM}_{42,1}$ & 13.87 & 0 & $4.99(0.03)$ & $4.99(0.08)$ & $-1.58(0.11)$ & $<0.001$ & 0.196 & 0.079 \\
\hline $\mathrm{POT}_{1}$ & 3.67 & 1 & $1.15(0.28)$ & $1.16(0.56)$ & $-0.95(0.34)$ & $<0.001$ & 0.049 & 0.021 \\
\hline \multicolumn{9}{|c|}{ Czech R (PX) } \\
\hline $\mathrm{BM}_{21,1}$ & 6.62 & 0 & $5.01(0.03)$ & $5.01(0.08)$ & $-1.59(0.11)$ & $<0.001$ & 0.094 & 0.035 \\
\hline $\mathrm{BM}_{42,1}$ & 7.19 & 0 & $5.01(0.03)$ & $5.01(0.08)$ & $-1.59(0.11)$ & $<0.001$ & 0.103 & 0.038 \\
\hline POT $_{1}$ & 3.44 & 2 & $0.1(0.75)$ & $0.14(0.93)$ & $-0.31(0.76)$ & $<0.001$ & 0.047 & 0.018 \\
\hline \multicolumn{9}{|c|}{ Lithuania (OMXV) } \\
\hline $\mathrm{BM}_{21,1}$ & 5.49 & 0 & $4.84(0.03)$ & $4.84(0.09)$ & $-1.56(0.12)$ & $<0.001$ & 0.076 & 0.031 \\
\hline $\mathrm{BM}_{42,1}$ & 7.68 & 0 & $4.84(0.03)$ & $4.84(0.09)$ & $-1.56(0.12)$ & $<0.001$ & 0.108 & 0.043 \\
\hline POT $_{1}$ & 2.20 & 9 & $10.72(0)$ & $11.67(0)$ & $4.27(0)$ & $<0.001$ & 0.029 & 0.013 \\
\hline \multicolumn{9}{|c|}{ Latvia (OMXR) } \\
\hline $\mathrm{BM}_{21,1}$ & 11.49 & 0 & $4.99(0.03)$ & $4.99(0.08)$ & $-1.58(0.11)$ & $<0.001$ & 0.17 & 0.056 \\
\hline $\mathrm{BM}_{42,1}$ & 15.78 & 0 & $4.99(0.03)$ & $4.99(0.08)$ & $-1.58(0.11)$ & $<0.001$ & 0.235 & 0.076 \\
\hline $\mathrm{POT}_{1}$ & 4.21 & 0 & $4.99(0.03)$ & $4.99(0.08)$ & $-1.58(0.11)$ & $<0.001$ & 0.057 & 0.02 \\
\hline \multicolumn{9}{|c|}{ Poland (WIG20) } \\
\hline $\mathrm{BM}_{21, \mathrm{I}}$ & 6.95 & 0 & $4.99(0.03)$ & $4.99(0.08)$ & $-1.58(0.11)$ & $<0.001$ & 0.099 & 0.035 \\
\hline $\mathrm{BM}_{42, \mathrm{I}}$ & 7.47 & 0 & $4.99(0.03)$ & $4.99(0.08)$ & $-1.58(0.11)$ & $<0.001$ & 0.107 & 0.038 \\
\hline $\mathrm{POT}_{1}$ & 4.00 & 2 & $0.1(0.75)$ & $0.13(0.94)$ & $-0.31(0.76)$ & $<0.001$ & 0.054 & 0.02 \\
\hline \multicolumn{9}{|c|}{ Slovakia (SAX) } \\
\hline $\mathrm{BM}_{21, \mathrm{I}}$ & 7.63 & 0 & $4.86(0.03)$ & $4.86(0.09)$ & $-1.56(0.12)$ & $<0.001$ & 0.097 & 0.054 \\
\hline $\mathrm{BM}_{42, \mathrm{I}}$ & 7.96 & 0 & $4.86(0.03)$ & $4.86(0.09)$ & $-1.56(0.12)$ & $<0.001$ & 0.101 & 0.056 \\
\hline $\mathrm{POT}_{1}$ & 3.52 & 0 & $4.86(0.03)$ & $4.86(0.09)$ & $-1.56(0.12)$ & $<0.001$ & 0.043 & 0.024 \\
\hline \multicolumn{9}{|c|}{ Hungary (BUX) } \\
\hline $\mathrm{BM}_{21, \mathrm{I}}$ & 7.43 & 0 & $4.91(0.03)$ & $4.91(0.09)$ & $-1.57(0.12)$ & $<0.001$ & 0.104 & 0.04 \\
\hline $\mathrm{BM}_{42, \mathrm{I}}$ & 8.67 & 0 & $4.91(0.03)$ & $4.91(0.09)$ & $-1.57(0.12)$ & $<0.001$ & 0.122 & 0.047 \\
\hline РОT $_{1}$ & 3.64 & 2 & $0.09(0.77)$ & $0.12(0.94)$ & $-0.28(0.78)$ & $<0.001$ & 0.048 & 0.02 \\
\hline \multicolumn{9}{|c|}{ Developed countries } \\
\hline \multicolumn{9}{|c|}{ England (UKX) } \\
\hline $\mathrm{BM}_{21,1}$ & 6.84 & 0 & $5.07(0.02)$ & $5.07(0.08)$ & $-1.6(0.11)$ & $<0.001$ & 0.095 & 0.037 \\
\hline $\mathrm{BM}_{42, \mathrm{I}}$ & 8.98 & 0 & $5.07(0.02)$ & $5.07(0.08)$ & $-1.6(0.11)$ & $<0.001$ & 0.127 & 0.049 \\
\hline POT $_{1}$ & 3.25 & 3 & $0.09(0.77)$ & $0.16(0.92)$ & $0.3(0.76)$ & $<0.001$ & 0.043 & 0.018 \\
\hline
\end{tabular}


Tab. 2: VaR forecasts for individual countries in period I

\begin{tabular}{|c|c|c|c|c|c|c|c|c|}
\hline & VaR 99\% & EX & Kupiec & Christoff & $T_{\mathrm{BP}}$ & A\&B & Caporin & CAE \\
\hline \multicolumn{9}{|c|}{ France (CAC) } \\
\hline $\mathrm{BM}_{21,1}$ & 7.52 & 0 & $5.11(0.02)$ & $5.11(0.08)$ & $-1.6(0.11)$ & $<0.001$ & 0.108 & 0.039 \\
\hline $\mathrm{BM}_{42,1}$ & 8.70 & 0 & $5.11(0.02)$ & $5.11(0.08)$ & $-1.6(0.11)$ & $<0.001$ & 0.125 & 0.045 \\
\hline $\mathrm{POT}_{1}$ & 4.05 & 0 & $5.11(0.02)$ & $5.11(0.08)$ & $-1.6(0.11)$ & $<0.001$ & 0.055 & 0.021 \\
\hline \multicolumn{9}{|c|}{ Germany (DAX) } \\
\hline $\mathrm{BM}_{21,1}$ & 8.76 & 0 & $5.05(0.02)$ & $5.05(0.08)$ & $-1.59(0.11)$ & $<0.001$ & 0.123 & 0.049 \\
\hline $\mathrm{BM}_{42,1}$ & 9.70 & 0 & $5.05(0.02)$ & $5.05(0.08)$ & $-1.59(0.11)$ & $<0.001$ & 0.137 & 0.054 \\
\hline POT $_{1}$ & 4.55 & 0 & $5.05(0.02)$ & $5.05(0.08)$ & $-1.59(0.11)$ & $<0.001$ & 0.062 & 0.025 \\
\hline
\end{tabular}

Source: Own study.

\subsubsection{Period III: post-crisis}

The results from the period III are presented in Table 4. They are clearly improved as every forecast can be considered to be precise recording not more than four exceedances, despite of still increased volatility on the markets in 2009. Therefore, all the methods can be considered as equally good in terms of its conservativeness. On the ground of cost functions, the POT method is again less demanding than both BM methods as Caporin and CAE functions are often two or three times smaller for POT method. Results obtained with those functions are however still significantly higher than in periods I and II which stem from extreme observations included in the analysis of period III.

Similarly to the period I, no evident differences were observed between individual countries within emerging and developing groups. The distinction between both groups is also rather imperceptible. It stems from the fact that the volatile data from previous period were used to forecast VaR and now, in the calmer period, there is rather small chance to extend the VaR level for each index.

The results obtained in period III can be summarised noting that in the post-crisis period the number of exceedances was decidedly limited compared with the crisis period. However, the VaR estimations can also be considered as too high to conclude that the obtained forecasts are of high quality in each of the considered cases.

\section{Conclusions}

$V a R$ is the main method of measuring market risk recommended and required by the Basel Committee on Banking Supervision. The research methodology is extensive and widely described in the literature; therefore, it can be adjusted depending on the purpose of the research. Financial data is characterised by leptokurtosis - their distributions tend to concentrate around the average, while at the same time heavy tails can be observed, that is, a greater chance of occurrence of outliers. The assumption of normal market behaviour changes in prices, daily return from the index or changes in the exchange rate may result in underestimation of the risk and expose the financial institution to high costs. VaR forecasting methods based on the EVT allow to take into account the heavy-tailed nature of the variable and may limit losses resulting from atypical events.

The aim of the presented study was to assess the quality of VaR forecasts in various states of the economic situation. Two approaches based on the EVT were compared: BM and the POT. Forecasts were made on data describing the daily closing prices of stock exchange indices, taking into account the logarithmic return rates. In total, 10 major indices in European countries were analysed, dividing them into two groups: the group of emerging countries (Bulgaria, Czech Republic, Lithuania, Latvia, Poland, Slovakia and Hungary) and the group of developed countries (England, France and Germany). Three states of economic situation were distinguished, 
Tab. 3: VaR forecasts for individual countries in period II

\begin{tabular}{|c|c|c|c|c|c|c|c|c|}
\hline & VaR 99\% & EX & Kupiec & Christoff & $T_{\mathrm{BP}}$ & $A \& B$ & Caporin & CAE \\
\hline \multicolumn{9}{|c|}{ Emerging countries } \\
\hline \multicolumn{9}{|c|}{ Bulgaria (SOFIX) } \\
\hline $\mathrm{BM}_{21, \|}$ & 11.15 & 1 & $1.12(0.29)$ & $1.13(0.57)$ & $-0.93(0.35)$ & $<0.001$ & 0.164 & 0.042 \\
\hline $\mathrm{BM}_{42, \|}$ & 11.24 & 1 & $1.12(0.29)$ & $1.13(0.57)$ & $-0.93(0.35)$ & $<0.001$ & 0.165 & 0.042 \\
\hline $\mathrm{POT}_{\|}$ & 3.55 & 26 & $78.09(0)$ & $94.62(0)$ & $15.12(0)$ & 0.002 & 0.048 & 0.02 \\
\hline \multicolumn{9}{|c|}{ Czech R (PX) } \\
\hline $\mathrm{BM}_{21, \|}$ & 7.05 & 6 & $3.53(0.06)$ & $5.96(0.05)$ & $2.21(0.03)$ & 0.001 & 0.097 & 0.035 \\
\hline $\mathrm{BM}_{42, \|}$ & 7.56 & 5 & $1.94(0.16)$ & $2.14(0.34)$ & $1.58(0.11)$ & 0.001 & 0.105 & 0.037 \\
\hline $\mathrm{POT}_{\|}$ & 3.4 & 22 & $58.1(0)$ & $65.4(0)$ & $12.36(0)$ & 0.003 & 0.047 & 0.021 \\
\hline \multicolumn{9}{|c|}{ Lithuania (OMXV) } \\
\hline $\mathrm{BM}_{21, \|}$ & 5.87 & 4 & $0.87(0.35)$ & $12.96(0)$ & $1.02(0.31)$ & $<0.001$ & 0.083 & 0.024 \\
\hline $\mathrm{BM}_{42, \|}$ & 7.86 & 3 & $0.13(0.72)$ & $15.65(0)$ & $0.38(0.71)$ & $<0.001$ & 0.115 & 0.031 \\
\hline $\mathrm{POT}_{\|}$ & 2.33 & 25 & $73.79(0)$ & $87.66(0)$ & $14.59(0)$ & 0.002 & 0.032 & 0.014 \\
\hline \multicolumn{9}{|c|}{ Latvia (OMXR) } \\
\hline $\mathrm{BM}_{21, \|}$ & 11.04 & 0 & $4.97(0.03)$ & $4.97(0.08)$ & $-1.58(0.11)$ & $<0.001$ & 0.163 & 0.046 \\
\hline $\mathrm{BM}_{42,11}$ & 14.94 & 0 & $4.97(0.03)$ & $4.97(0.08)$ & $-1.58(0.11)$ & $<0.001$ & 0.224 & 0.063 \\
\hline $\mathrm{POT}_{\|}$ & 4.06 & 11 & $16.1(0)$ & $28.57(0)$ & $5.46(0)$ & 0.001 & 0.055 & 0.02 \\
\hline \multicolumn{9}{|c|}{ Poland (WIG20) } \\
\hline $\mathrm{BM}_{21, \|}$ & 7.15 & 2 & $0.11(0.74)$ & $0.14(0.93)$ & $-0.32(0.75)$ & $<0.001$ & 0.096 & 0.035 \\
\hline $\mathrm{BM}_{42,11}$ & 8 & 1 & $1.18(0.28)$ & $1.19(0.55)$ & $-0.95(0.34)$ & $<0.001$ & 0.109 & 0.038 \\
\hline $\mathrm{POT}_{\|}$ & 3.94 & 16 & $33.15(0)$ & $34(0)$ & $8.58(0)$ & 0.001 & 0.05 & 0.022 \\
\hline \multicolumn{9}{|c|}{ Slovakia (SAX) } \\
\hline $\mathrm{BM}_{21, \|}$ & 7.42 & 0 & $4.93(0.03)$ & $4.93(0.09)$ & $-1.57(0.12)$ & $<0.001$ & 0.093 & 0.052 \\
\hline $\mathrm{BM}_{42,11}$ & 7.74 & 0 & $4.93(0.03)$ & $4.93(0.09)$ & $-1.57(0.12)$ & $<0.001$ & 0.097 & 0.054 \\
\hline $\mathrm{POT}_{\|}$ & 3.41 & 3 & $0.12(0.73)$ & $0.19(0.91)$ & $0.35(0.72)$ & $<0.001$ & 0.04 & 0.024 \\
\hline \multicolumn{9}{|c|}{ Hungary (BUX) } \\
\hline $\mathrm{BM}_{21, \|}$ & 7.27 & 6 & $3.56(0.06)$ & $11.69(0)$ & $2.23(0.03)$ & 0.001 & 0.102 & 0.034 \\
\hline $\mathrm{BM}_{42,11}$ & 8.32 & 4 & $0.77(0.38)$ & $4.88(0.09)$ & $0.95(0.34)$ & $<0.001$ & 0.118 & 0.038 \\
\hline $\mathrm{POT}_{\|}$ & 3.57 & 14 & $25.78(0)$ & $27.32(0)$ & $7.31(0)$ & 0.002 & 0.048 & 0.02 \\
\hline \multicolumn{9}{|c|}{ Developed countries } \\
\hline \multicolumn{9}{|c|}{ England (UKX) } \\
\hline $\mathrm{BM}_{21, \mathrm{II}}$ & 6.99 & 3 & $0.08(0.77)$ & $0.16(0.92)$ & $0.3(0.77)$ & $<0.001$ & 0.099 & 0.032 \\
\hline $\mathrm{BM}_{42, \|}$ & 8.91 & 1 & $1.21(0.27)$ & $1.22(0.54)$ & $-0.97(0.33)$ & $<0.001$ & 0.129 & 0.039 \\
\hline $\mathrm{POT}_{\|}$ & 3.25 & 16 & $32.82(0)$ & $33.7(0)$ & $8.51(0)$ & 0.001 & 0.045 & 0.018 \\
\hline
\end{tabular}


Tab. 3: VaR forecasts for individual countries in period II

\begin{tabular}{|c|c|c|c|c|c|c|c|c|}
\hline & VaR 99\% & EX & Kupiec & Christoff & $T_{\mathrm{BP}}$ & A\&B & Caporin & CAE \\
\hline \multicolumn{9}{|c|}{ France (CAC) } \\
\hline $\mathrm{BM}_{21, \|}$ & 7.28 & 2 & $0.13(0.72)$ & $0.16(0.92)$ & $-0.35(0.73)$ & $<0.001$ & 0.1 & 0.035 \\
\hline $\mathrm{BM}_{42,11}$ & 8.65 & 1 & $1.24(0.27)$ & $1.25(0.54)$ & $-0.98(0.33)$ & $<0.001$ & 0.121 & 0.041 \\
\hline $\mathrm{POT}_{\|}$ & 3.93 & 16 & $32.6(0)$ & $32.6(0)$ & $8.47(0)$ & 0.001 & 0.052 & 0.022 \\
\hline \multicolumn{9}{|c|}{ Germany (DAX) } \\
\hline $\mathrm{BM}_{21, \|}$ & 8.52 & 0 & $5.09(0.02)$ & $5.09(0.08)$ & $-1.6(0.11)$ & $<0.001$ & 0.12 & 0.04 \\
\hline $\mathrm{BM}_{42,11}$ & 9.74 & 0 & $5.09(0.02)$ & $5.09(0.08)$ & $-1.6(0.11)$ & $<0.001$ & 0.138 & 0.045 \\
\hline $\mathrm{POT}_{\|}$ & 4.41 & 13 & $22.06(0)$ & $22.22(0)$ & $6.62(0)$ & 0.001 & 0.059 & 0.024 \\
\hline
\end{tabular}

Source: Own study.

Tab. 4: VaR forecasts for individual countries in period III

\begin{tabular}{|c|c|c|c|c|c|c|c|c|}
\hline & VaR 99\% & EX & Kupiec & Christoff & $T_{\mathrm{BP}}$ & $A \& B$ & Caporin & CAE \\
\hline \multicolumn{9}{|c|}{ Emerging countries } \\
\hline \multicolumn{9}{|c|}{ Bulgaria (SOFIX) } \\
\hline $\mathrm{BM}_{21, \mathrm{II}}$ & 12.31 & 0 & $5.01(0.03)$ & $5.01(0.08)$ & $-1.59(0.11)$ & $<0.001$ & 0.179 & 0.064 \\
\hline $\mathrm{BM}_{42, \mathrm{II}}$ & 11.9 & 0 & $5.01(0.03)$ & $5.01(0.08)$ & $-1.59(0.11)$ & $<0.001$ & 0.173 & 0.062 \\
\hline $\mathrm{POT}_{\mathrm{III}}$ & 4.92 & 0 & $5.01(0.03)$ & $5.01(0.08)$ & $-1.59(0.11)$ & $<0.001$ & 0.068 & 0.025 \\
\hline \multicolumn{9}{|c|}{ Czech R (PX) } \\
\hline $\mathrm{BM}_{21, \mathrm{II}}$ & 10.2 & 0 & $5.05(0.02)$ & $5.05(0.08)$ & $-1.59(0.11)$ & $<0.001$ & 0.145 & 0.055 \\
\hline $\mathrm{BM}_{42, \mathrm{II}}$ & 11.88 & 0 & $5.05(0.02)$ & $5.05(0.08)$ & $-1.59(0.11)$ & $<0.001$ & 0.169 & 0.064 \\
\hline $\mathrm{POT}_{\mathrm{III}}$ & 4.45 & 2 & $0.11(0.74)$ & $0.15(0.93)$ & $-0.32(0.75)$ & $<0.001$ & 0.061 & 0.024 \\
\hline \multicolumn{9}{|c|}{ Lithuania (OMXV) } \\
\hline $\mathrm{BM}_{21, \mathrm{III}}$ & 7.72 & 0 & $4.93(0.03)$ & $4.93(0.09)$ & $-1.57(0.12)$ & $<0.001$ & 0.11 & 0.044 \\
\hline $\mathrm{BM}_{42, \mathrm{II}}$ & 10.02 & 0 & $4.93(0.03)$ & $4.93(0.09)$ & $-1.57(0.12)$ & $<0.001$ & 0.142 & 0.057 \\
\hline $\mathrm{POT}_{\mathrm{III}}$ & 3.2 & 1 & $1.12(0.29)$ & $1.13(0.57)$ & $-0.93(0.35)$ & $<0.001$ & 0.046 & 0.019 \\
\hline \multicolumn{9}{|c|}{ Latvia (OMXR) } \\
\hline $\mathrm{BM}_{21, \mathrm{III}}$ & 13.06 & 0 & $4.97(0.03)$ & $4.97(0.08)$ & $-1.58(0.11)$ & $<0.001$ & 0.192 & 0.065 \\
\hline $\mathrm{BM}_{42, \mathrm{II}}$ & 16.25 & 0 & $4.97(0.03)$ & $4.97(0.08)$ & $-1.58(0.11)$ & $<0.001$ & 0.24 & 0.081 \\
\hline $\mathrm{POT}_{\mathrm{III}}$ & 4.85 & 0 & $4.97(0.03)$ & $4.97(0.08)$ & $-1.58(0.11)$ & $<0.001$ & 0.07 & 0.024 \\
\hline \multicolumn{9}{|c|}{ Poland (WIG20) } \\
\hline $\mathrm{BM}_{21, \mathrm{III}}$ & 8.45 & 0 & $5.07(0.02)$ & $5.07(0.08)$ & $-1.6(0.11)$ & $<0.001$ & 0.121 & 0.044 \\
\hline $\mathrm{BM}_{42,111}$ & 9.46 & 0 & $5.07(0.02)$ & $5.07(0.08)$ & $-1.6(0.11)$ & $<0.001$ & 0.136 & 0.049 \\
\hline $\mathrm{POT}_{\text {III }}$ & 4.6 & 0 & $5.07(0.02)$ & $5.07(0.08)$ & $-1.6(0.11)$ & $<0.001$ & 0.064 & 0.024 \\
\hline
\end{tabular}


Tab. 4: VaR forecasts for individual countries in period III

\begin{tabular}{|c|c|c|c|c|c|c|c|c|}
\hline & VaR 99\% & EX & Kupiec & Christoff & $T_{\mathrm{BP}}$ & A\&B & Caporin & CAE \\
\hline \multicolumn{9}{|c|}{ Slovakia (SAX) } \\
\hline $\mathrm{BM}_{21, \mathrm{II}}$ & 10.1 & 1 & $1.16(0.28)$ & $1.17(0.56)$ & $-0.95(0.34)$ & $<0.001$ & 0.133 & 0.065 \\
\hline $\mathrm{BM}_{42, \mathrm{II}}$ & 11.41 & 1 & $1.16(0.28)$ & $1.17(0.56)$ & $-0.95(0.34)$ & $<0.001$ & 0.151 & 0.073 \\
\hline $\mathrm{POT}_{\text {III }}$ & 3.72 & 4 & $0.78(0.38)$ & $0.91(0.63)$ & $0.96(0.34)$ & 0.001 & 0.048 & 0.025 \\
\hline \multicolumn{9}{|c|}{ Hungary (BUX) } \\
\hline $\mathrm{BM}_{21, \mathrm{II}}$ & 9.64 & 0 & $5.09(0.02)$ & $5.09(0.08)$ & $-1.6(0.11)$ & $<0.001$ & 0.139 & 0.048 \\
\hline $\mathrm{BM}_{42, \mathrm{II}}$ & 11.36 & 0 & $5.09(0.02)$ & $5.09(0.08)$ & $-1.6(0.11)$ & $<0.001$ & 0.165 & 0.057 \\
\hline $\mathrm{POT}_{\mathrm{III}}$ & 4.48 & 4 & $0.73(0.39)$ & $0.86(0.65)$ & $0.93(0.35)$ & $<0.001$ & 0.062 & 0.023 \\
\hline \multicolumn{9}{|c|}{ Developed countries } \\
\hline \multicolumn{9}{|c|}{ England (UKX) } \\
\hline $\mathrm{BM}_{21, \mathrm{III}}$ & 8.73 & 0 & $5.07(0.02)$ & $5.07(0.08)$ & $-1.6(0.11)$ & $<0.001$ & 0.125 & 0.046 \\
\hline $\mathrm{BM}_{42, \mathrm{II}}$ & 10.61 & 0 & $5.07(0.02)$ & $5.07(0.08)$ & $-1.6(0.11)$ & $<0.001$ & 0.153 & 0.056 \\
\hline $\mathrm{POT}_{\text {III }}$ & 3.9 & 0 & $5.07(0.02)$ & $5.07(0.08)$ & $-1.6(0.11)$ & $<0.001$ & 0.054 & 0.02 \\
\hline \multicolumn{9}{|c|}{ France (CAC) } \\
\hline $\mathrm{BM}_{21, \mathrm{III}}$ & 8.51 & 0 & $5.17(0.02)$ & $5.17(0.08)$ & $-1.61(0.11)$ & $<0.001$ & 0.123 & 0.042 \\
\hline $\mathrm{BM}_{42, \mathrm{II}}$ & 9.69 & 0 & $5.17(0.02)$ & $5.17(0.08)$ & $-1.61(0.11)$ & $<0.001$ & 0.141 & 0.048 \\
\hline $\mathrm{POT}_{\text {III }}$ & 4.49 & 2 & $0.14(0.71)$ & $0.17(0.92)$ & $-0.36(0.72)$ & $<0.001$ & 0.062 & 0.023 \\
\hline \multicolumn{9}{|c|}{ Germany (DAX) } \\
\hline $\mathrm{BM}_{21, \mathrm{III}}$ & 9.3 & 0 & $5.13(0.02)$ & $5.13(0.08)$ & $-1.61(0.11)$ & $<0.001$ & 0.132 & 0.051 \\
\hline $\mathrm{BM}_{42, \mathrm{II}}$ & 10.25 & 0 & $5.13(0.02)$ & $5.13(0.08)$ & $-1.61(0.11)$ & $<0.001$ & 0.145 & 0.056 \\
\hline $\mathrm{POT}_{\text {III }}$ & 4.79 & 0 & $5.13(0.02)$ & $5.13(0.08)$ & $-1.61(0.11)$ & $<0.001$ & 0.066 & 0.026 \\
\hline
\end{tabular}

Source: Own study.

which checked the quality of VaR forecasts: the precrisis period (01 January 2007-31 December 2007), the crisis period (01 January 2008-31 December 2008) and the post-crisis period (01 January 2009-31 December 2009).

There is no clear answer which method provides better VaR estimations: POT or BM. VaR estimations based on BM methods make the estimations more conservative than POT method. They give more efficient results during crisis period where less exceedances are observed, but it may be more costly for financial institutions during calm periods, where cost functions are simply too high to implement such tools.
The main conclusion from the obtained results is the too slow process of adapting static EVT-based forecasts to market movements. While in the pre-crisis period the results were satisfactory, in the period of crisis VaR forecasts were too often exceeded and it was confirmed by Kupiec and Christoffersen tests. Both of them also indicate that the predicted and observed number of exceedances differs not only in crisis period, but also in calm periods where VaR is overestimated or underestimated. In addition to the overflows themselves, the cost functions should also be taken into account which indicate the costs of underestimation in periods of strong market movements as well as overestimation of forecasts in the period of calm. 
While the number of exceedances varies significantly between periods of low and increased volatility, the Caporin and CAE functions were similar in every period. It means that the error of estimation occurs in all periods, but it is its direction that varies. During beforecrisis period, the VaR was overestimated in most cases; on the other hand, it was underestimated in crisis period mainly for POT method. It is confirmed by Backtesting criterion statistic, which shows that in first and last periods the negative values are mostly observed, while in the crisis-period positive values of statistic mainly occur, indicating $\mathrm{VaR}$ overestimation and underestimation in these periods, respectively.

Another important conclusion from the research is the suggestion that emerging markets are more volatile than the developed ones. Comparison of number of exceedances, especially in crisis period, indicates this fact. For all the methods, the number of exceedances is much lower in post-crisis period. The value of Abad and Benito function indicates that even though the number of exceedances was small, the exceedances themselves were much more meaningful than in emerging markets and could lead to significant losses.

The results obtained show that unconditional EVT models do not provide VaR forecasts of sufficient quality, especially during the crisis, in a period when - due to their nature - they should protect against the risk the most. It seems that the main weakness of these models is the inability to account for the dynamics of variation in conditional variance. It is possible to combine the concepts of EVT and models that take into account the GARCH process in the ranges of return on financial instruments, and it seems that these models allow to obtain better VaR forecasts (com. Abad et al. 2013).

\section{References}

[1] Abad, P., Benito, S., \& Lopez, C. (2013). A comprehensive review of value at risk methodologies. The Spanish Review of Financial Economics, 12(1), 15-32.

[2] Allen, D., Singh, A., \& Powell, R. (2011). Value at Risk estimation using extreme value theory. $E C U$ Publications. Retrieved from http://ro.ecu.edu.au/ ecuworks2011/.
[3] Alves, M., \& Santos, P. (2013). Conditional EVT for VAR estimation: comparison with a new independence test. In J. Lita da Silva (Ed.), Advances in regression, survival analysis, extreme values, Markov processes and other statistical applications (pp. 183191). Berlin, Germany: Springer.

[4] Angelidis, T., Benos, A., \& Degiannakis, S. (2007). A robust VAR model under different time periods and weighting schemes. Review of Quantitative Finance and Accounting, 28, 187-201.

[5] Artzner, P., Eber, J.-M., \& Heath, D. (1999). Coherent measures of risk. Mathematical Finance, 9, 203-228.

[6] Balkema, A., \& de Haan, L. (1974). Residual lifetime at great age. Annals of Probability, 2, 792-804.

[7] Bao, Y., Lee, T.-H., \& Saltoglu, B. (2006). Evaluating predictive performance of Value-at-Risk models in emerging markets: a reality check. Journal of Forecasting, 25, 101-128.

[8] BCBS. (1996). Supervisory framework for the use of 'backtesting' in conjuction with the internal models approach to market risk capital requirements. Basel: Basel Committee on Banking Supervision. Retrieved from https://www.bis.org/publ/bcbs22.htm.

[9] Bee, M., \& Miorelli, F. (2010). Dynamic VaR models and the peaks over threshold method for market risk measurement: an empirical investigation during a financial crisis. Department of Economics Working Papers 1009, Department of Economics, University of Trento, Italia.

[10] Bhattacharyya, M., \& Ritolia, G. (2008). Conditional VaR using EVT - towards a planned margin scheme. International Review of Financial Analysis, 17, 382-395.

[11] Bollerslev, T. (1986). Generalized autoregressive conditional heteroskedasticity. Journal of Econometrics, 31, 307-327.

[12] Bollerslev, T., Todorov, V., \& Li, S. (2013). Jump tails, extreme dependencies, and the distribution of stock returns. Journal of Econometrics, 172(2), 307-324.

[13] Bommier, E. (2014). Peaks-over-threshold modelling of environmental data. Retrieved from https:// uu.diva-portal.org/smash/get/diva2:760802/ FULLTEXT01.pdf.

[14] Bystrom, H. (2001). Managing risks in tranquil and volatile markets using conditional extreme value 
theory. International Review of Financial Analysis, 13(2), 133-152.

[15] Caires, S. (2009). A comparative simulation study of the annual Maxima and the peaks-over-threshold methods. "Hydraulic Engineering Reports" (Deltares Report 1200264-002). Retrieved from https:// repository.tudelft.nl/islandora/object/ uuid:143b0f1e-f61e-44ab-8da3-9241970d915b?colle ction=research.

[16] Caporin, M. (2008). Evaluating Value-at-Risk measures in the presence of long memory conditional volatility. Journal of Risk, 10, 79-110.

[17] Chlebus, M. (2014). Market risk measuring using value at risk - two-step approach ( $\mathrm{PhD}$ thesis), Faculty of Economic Sciences, University of Warsaw.

[18] Christoffersen, P. (1998). Evaluating interval forecasting. International Economic Review, 39, 841862.

[19] Darbha, G. (2001). Value-at-Risk for fixed income portfolios-acomparison ofalter-nativemodels. Mumbai: National Stock Exchange. Retrieved from https:/ / www.researchgate.net/publication/228607410_ Value-at-Risk_for_Fixed_Income_portfolios-A_ comparison_of_alternative_models.

[20] Da Silva, A., \& de Melo Mendes, B. V. (2003). Valueat-Risk and extreme returns in Asian stock markets. International Journal of Business, 8(1), 24.

[21] Embrechts, P., Kluppelberg, C., \& Mikosch, T. (1997). Modelling extremal events for Insurance and Finance. Springer-Verlag, 295-305.

[22] Engle, R. (1982). Autoregressive Conditional Heteroscedasticity with Estimates of the Variance of United Kingdom Inflation. Econometrica, 50, 9871007.

[23] Engle, R., \& Patton, A. (2001). What good is a volatility model? Quantitative Finance, Vol. 1, 237245.

[24] Engle, R. F., \& Manganelli, S. (2004). CAViaR: conditional autoregressive value at risk by regression quantiles. Journal of Business $\mathcal{E}$ Economic Statistics, 22(4), 367-381.

[25] Ergun, T., \& Jun, J. (2010). Time-varying higherorder conditional moments and forecasting intraday VaR and expected shortfall. The Quarterly Review of Economics and Finance, 50, 264-272.
[26] Fisher, R., \& Tippett, L. (1928). Limiting forms of the frequency distribution of the largest or smallest member of a sample. Proceedings of the Cambridge Philosophical Society, 180-190.

[27] Flugentiusson, H. (2012). Push it to the limit. Testing the usefulness of extreme value theory in electricity markets. Lund University Publications. Retrieved from http://lup.lub.lu.se/luur/download?func $=$ downloadFile \&recordOId $=3166413 \&$ fileOId $=3166414$.

[28] Gencay, R., \& Selcuk, F. (2004). Extreme value theory and Value-at-Risk: Relative performance in emerging markets. International Journal of Forecasting, 20, 287-303.

[29] Gencay, R., Selcuk, F., \& Ulugulyagci, A. (2003). High volatility, thick tails and extreme value theory in Value-at-Risk estimation. Insurance: Mathematics and Economics, 33, 337-356.

[30] Kourouma, L., Dupre, D., Sanfilippo, G., \& Taramasco, O. (2010). Extreme value at risk and expected shortfall during financial crisis. Retrieved from https:// ssrn.com/abstract=1744091; doi:10.2139/ssrn.1744091.

[31] Kupiec, P. (1995). Techniques for verifying the accuracy of risk measurement models, Journal of Derivatives, 3(2), 73-84.

[32] Lopez, J. (1999). Methods for evaluating Value-atRisk estimates. Federal Reserve Bank of San Francisco Economic Review, 2, 3-17.

[33] Manganelli, S., \& Engle, R. (2001). Value at Risk Models in Finance. ECB Working Paper No. 75, available at SSRN: https://ssrn.com/ abstract $=356220$

[34] Marimoutou, V., Raggad, B., \& Trabelsi, A. (2009). Extreme value theory and value at risk: application to oil market. Energy Economics, 31, 519-530.

[35] Marinelli C., d'Addona S., \& Rachev T. (2007). A comparison of some univariate models for Valueat-Risk and expected shortfall. International Journal of Theoretical and Applied Finance, 10(06), 1043-1075.

[36] Mutu, S., Balogh, P., \& Moldovan, D. (2011). The efficiency of value at risk models on central and eastern European stock markets. International Journal of Mathematics and Computers in Simulation, 5, 110-117. 
[37] Nozari, M., Raei, S., Jahanguin, P., \& Bahramgiri, M. (2010). A comparison of heavy-tailed estimates and filtered historical simulation: evidence from emerging markets. International Review of Business Papers, 6(4), 347-359.

[38] Pagan, A. (1996). The econometrics of financial markets. Journal of Empirical Finance, 3, 15-102.

[39] Pickands, J. (1975). Statistical inference using extreme order statistics. Annals of Statistics, 3, 119131. 